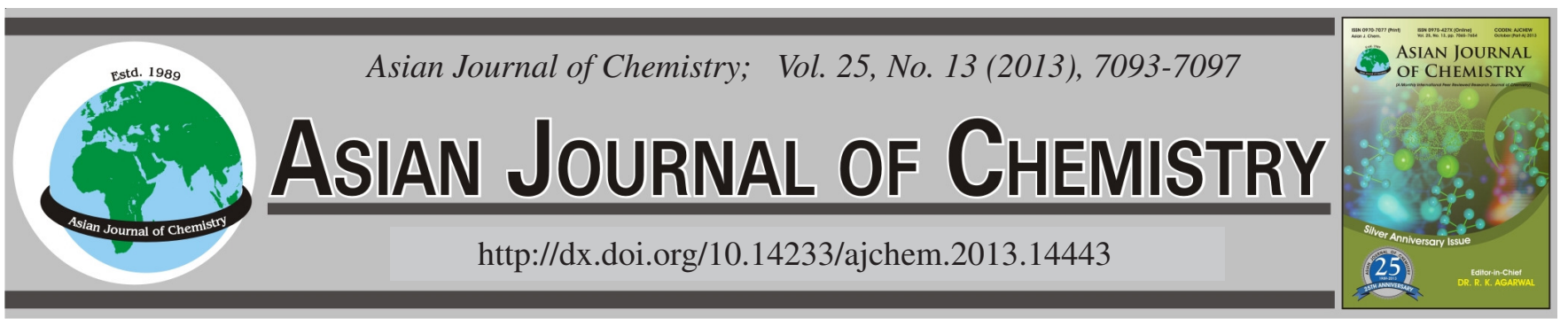

\title{
Quantitative Determination of Triterpenoidal Saponins in Platycodi radix and Its Variation in Different Regions of Korean Peninsula: A Herbal Plant Used as Traditional Medicine
}

\section{S.-J. Kim ${ }^{1, *}$, M. Valan Arasu ${ }^{1}$, N.A. Al-Dhabi ${ }^{2}$, D.-S. Yoo ${ }^{3}$, M.-H. PARK ${ }^{4}$, Y.-S. Shin ${ }^{5}$ and S.-W. LeE, ${ }^{5 *}$}

${ }^{1}$ Department of Biological Environment and Chemistry, College of Agriculture and Life Sciences, Chungnam National University, Daejeon 305-764, Republic of Korea

${ }^{2}$ Department of Botany and Microbiology, Addiriyah Chair for Environmental Studies, College of Science, King Saud University, Riyadh 11451, Saudi Arabia

${ }^{3}$ Korea Research Institute of Chemical Technology, Daejeon 305-600, Republic of Korea

${ }^{4}$ Department of Horticultural Crop Research, National Institute of Horticultural and Herbal Science (NIHHS), RDA, 475 Imok-dong, Jangan-gu, Suwon 440-706, Republic of Korea

${ }^{5}$ Department of Herbal Crop Research, National Institute of Horticultural \& Herbal Science, RDA, Eumseong 369-873, Republic of Korea

*Corresponding author: Fax: +82 42 8217142; Tel: +82 42 8216738; E-mail: kimsunju@cnu.ac.kr; swlee1004@korea.kr

(Received: 16 August 2012;

Accepted: 14 June 2013)

AJC-13649

This survey was undertaken in different provinces in order to evaluate the contents of triterpenoidal saponins in Platycodi radix and its
variation in different regions of Korea. HPLC and ESI-MS analysis were conducted for identification and quantification of ten know and
four unknown compounds. Fourteen saponin compounds such as deapio-platycoside E, platycoside E, platycodin D3, platyconic acid A,
platycodin D2, platycodin D, mixture of polygalacin D2 and 3'-O-acetyl-platycodin D, polygalacin D, 3'-O-acetyl-polygalacin D, 2'-O-
acetyl-platycodin D and four unknown compounds widely ranged from 2,643 to 23,599 mg/kg dry weight (DW) in the 3-year-old roots
and from 5,693 to $34,205 \mathrm{mg} / \mathrm{kg}$ DW in the 2 -year-old roots, respectively. Since KFDA has not assigned any individual compounds for
the quality control of Platycodi radix, we would suggest using Platycodi radix from the region of Jinan because the samples contain
moderate total saponins contents.

Key Words: Platycodi radix, Platycodin D, Triterpenoidal saponins, HPLC-ELSD, LC/ESI-MS.

ᄂ - - - - - - - - - - - - - - - - - - - - - - - - - - - -

\section{INTRODUCTION}

Platycodi radix, the root of Platycodon grandiflorum A. DC (Companulaceae), is a perennial herb commonly known as balloon flower and widely spread in Northeast Asia including China, Japan and Korea. It has been used as a traditional oriental medicine for centuries due to several potent effects on the treatment of cough, cold, sore throats, tonsillitis, bronchitis and chest congestion ${ }^{1}$. The primary active constituents of Platycodi radix are well known as platycosides and triterpenoidal saponins. Approximately 20 types of platycosides have been reported from Platycodi radix ${ }^{2}$. The platycoside molecules are classified as bidesmosidic saponins with two sugar moieties; a glucose unit attached through an ether linkage at C-3 of a triterpene and others containing arabinose, rhamnose and xylose in sequence attached through an ester linkage between C-28 and arabinose. These bidesmosidic saponins were easily transformed into mono-desmosidic saponins, for example, glucosyl platycodigenin, by the alkaline hydrolysis of the esterified sugar at C-283. Platycodin D and platycoside E were represented as the major platycosides of Platycodi radix, are potentially active against brain diseases and are cytotoxic to human tumour cells ${ }^{4}$. Platycodin A and $\mathrm{C}$ are used as a neuroprotective agent ${ }^{5}$ whereas, platycodin $\mathrm{D}$ has antiobesity effects $^{6}$ and is a potent adjuvant of hepatitis B antigen ${ }^{7}$. Therefore, quality control of the active medicinal platycosides in Platycodi radix is necessary to achieve consistent medicinal activity. In South Korea, two kinds of commercial Platycodi radix are available from native, among that common Platycodi radix cultivated for 2 or 3 years; the other Jangseng ( $P$. grandiflorum) is cultivated over 20 years by changing cultivation places in every 3 years. Up to now approximately 20 saponins from Platycodi radix have been separated by high performance liquid chromatography (HPLC) or HPLC-evaporative light scattering detector (ELSD) and identified by LCelectrospray ionization-mass spectrometry (ESI-MS) since $1972^{8,9}$. The chemical constituents of Platycodi radix are different based on the grown places and the length of cultivation 
periods. However, there is still limited scientific information with individual saponins of Platycodi radix grown in different places and the length of cultivation periods in South Korea. In the present study, the saponin compositions of 30 Platycodi radix samples were collected and measured from 19 places of nationwide in Republic of Korea.

\section{EXPERIMENTAL}

HPLC-grade methanol used for extraction was purchased from Fisher Scientific (Pittsburg, PA). HPLC-grade mobile phase, acetonitrile (J.T. Baker, Phillipsburg, NJ) and water purified using a Milli-Q system (Millipore, Molsheim, France), was filtered through Millipore $0.45 \mu \mathrm{m}$ membrane filters and degassed for $20 \mathrm{~min}$ by sonication before use. Ammonium acetate, formic acid, acetic acid, phosphoric acid, potassium phosphate dibasic and triethylamine were obtained from Sigma-Aldrich Chemical Co. (St. Louis, MO, USA). Ten pure saponins were isolated from the methanol extract of Platycodi radix following methods described in the literature ${ }^{2}$. The purity of the saponins was determined to be more than $95 \%$ compared with the peak areas detected by HPLC-ELSD.

Two and three years old roots named as PR-1 and PR-2 (PR: Platycodi radix) were collected from 19 places of nationwide in Republic of Korea from middle to end of April, 2009. The roots were stored at less than $4{ }^{\circ} \mathrm{C}$ in until the process of saponins extraction. They were washed with tap water, rinsed with distilled water and lyophilized.

Extraction of samples: Freeze-dried plant powder $(1 \mathrm{~g})$ was placed in a $50 \mathrm{~mL}$ centrifuge conical tube and extracted with $30 \mathrm{~mL}$ of HPLC-grade methanol. The mixture was vigorously vortexed for $3 \mathrm{~min}$ and allowed to stand for seven days at ambient temperature. The sample was monitored by vortexing for 1 min every day three times. The supernatant was separated by centrifugation at $1,000 \mathrm{~g}$ for $10 \mathrm{~min}$ and filtered through a No. 2 filter paper. The solvent is evaporated until dryness and re-dissolved in a minimum volume $(2 \mathrm{~mL})$ of $\mathrm{H}_{2} \mathrm{O}$. The solution was filtered through a $0.45 \mu \mathrm{m}$ of syringe filter (PVDF, 25 mm, Millipore Co., Billerica, MA, USA) into a HPLC vial. All samples were analyzed with three replications.

HPLC-ELSD analysis: The filtrate was then analyzed by an HPLC NS-3000i system (Futecs Co., Ltd, Daejeon, Korea) equipped with a Model 100 ELSD (Softa Co., Westminster, CO, USA). Platycodi radix saponins were separated using a Chemcobond 5-ODS-H column $(150 \mathrm{~mm} \times 4.6$ $\mathrm{mm}$ i.d., $3 \mu \mathrm{m}$ particle size; Chemco Scientific, Osaka, Japan). The ELSD was set to a probe temperature of $100^{\circ} \mathrm{C}$, a gain of seven and the nebulizer gas was nitrogen and adjusted to $36 \mathrm{psi}(250 \mathrm{kPa})$. The column oven temperature of LC was set at $40^{\circ} \mathrm{C}$. The injection sling was $20 \mu \mathrm{L}$. The solvent system was delivered at a rate of $1.0 \mathrm{~mL} / \mathrm{min}$ and consisted of a mixture of (A) $30 \mathrm{mM}$ acetic acid: $0.07 \%$ formic acid:methanol (85:5:10, v/v/v) and (B) $25 \mathrm{mM}$ acetic acid: $0.05 \%$ formic acid:methanol $(72: 5: 23, \mathrm{v} / \mathrm{v} / \mathrm{v})$. The initial mobile phase composition was $0 \%$ solvent $\mathrm{B}$, followed by a linear gradient from $0-15 \%$ of solvent B in $5 \mathrm{~min}$, to $38 \%$ in $28 \mathrm{~min}$, to $40 \%$ in $33 \mathrm{~min}$, to $43 \%$ in $53 \mathrm{~min}$, to $60 \%$ in $63 \mathrm{~min}$, to $100 \%$ in 71 min and then holding at $100 \%$ solvent B for an additional $24 \mathrm{~min}$. The content of saponins was estimated by comparing the corresponding peak area of the chromatograms of the samples with that of the purified platycodin D in our laboratory.

HPLC/ESI-MS analysis for identification of saponins: The extracts were passed through a $0.45 \mu \mathrm{m}$ filter and applied to an HPLC/ESI-MS system consisting of Agilent 1200 series HPLC (Agilent Technologies Inc., Palo Alto, CA, USA) and an ABI 3200 Q Trap (Applied Biosystems Inc, Foster City, CA, USA). The separation was carried out on an ODS-H column $(100 \mathrm{~mm} \times 2.1 \mathrm{~mm}$ i.d. $3.5 \mu \mathrm{m}$ particle size; Shiseido, Tokyo, Japan) at a flow rate of $0.2 \mathrm{~mL} / \mathrm{min}$. The ion source was set to run in the negative ion mode $(-3.5 \mathrm{kV})$ with $\mathrm{N}_{2}$ sheath gas at a nebulizing pressure of $50 \mathrm{psi}(344 \mathrm{kPa})$. The capillary temperature and voltage were set at $365^{\circ} \mathrm{C}$ and -15 $\mathrm{V}$, respectively. The ion trap MS analysis was carried out with $\mathrm{N}_{2}$ as the collision gas and the normalized collision energy was set to $30 \%$. The total ion chromatogram was obtained from $150-2,000 \mathrm{~m} / \mathrm{z}$. The LC solvent system was delivered at a rate of $1.0 \mathrm{~mL} / \mathrm{min}$ and consisted of a mixture of (A) $30 \mathrm{mM}$ acetic acid: $0.07 \%$ formic acid: methanol $(85: 5: 10, \mathrm{v} / \mathrm{v} / \mathrm{v})$ and (B) $25 \mathrm{mM}$ acetic acid: $0.05 \%$ formic acid: methanol (72:5:23, $\mathrm{v} / \mathrm{v} / \mathrm{v})$.

\section{RESULTS AND DISCUSSION}

Identification of triterpenoidal saponins: A mixture of 14 platycosides was analyzed by gradient solution, containing different buffers with varying buffering condition, because $\mathrm{pH}$ of the mobile phase plays an important role in determining the chromatographic retention time of acidic or basic compounds ${ }^{10}$. The ESI-MS spectral data showed various triterpenoidal saponins quantified with ELSD; 14 saponins were separated (Fig. 1) and identified with 4 unknown compounds as deapioplatycoside E (peak No. 1 of HPLC-ELSD chromatogram), platycoside E (2), platycodin D3 (3), platyconic acid A (4), unknown-1 (5), platycodin D2 (6), platycodin D (7), unknown2 (8), mixture of (polygalacin D2 and 3'-O-acetyl-platycodin D) (9), polygalacin D (10), 3'-O-acetyl-polygalacin D (11), unknown-3 (12), 2'-O-acetyl-platycodin D (13) and unknown4 (14) (Table-1).

\begin{tabular}{clc}
\multicolumn{3}{c}{ TABLE-1 } \\
\multicolumn{3}{c}{$\begin{array}{c}\text { SAPONINS SEPARATED FROM THE ROOT OF } \\
\text { Platycodi radix COLLECTED IN SOUTH KOREA }\end{array}$} \\
\hline No. & \multicolumn{1}{c}{ Compounds } & $\mathrm{m} / \mathrm{z}[\mathrm{M}+\mathrm{H}]^{+}$ \\
\hline 1 & Deapio-platycoside E & 1416 \\
2 & Platycoside E & 1548 \\
3 & Platycodin D3 & 1386 \\
4 & Platyconic acid A & 1238 \\
5 & Unknown-1 & - \\
6 & Platycodin D2 & 1386 \\
7 & Platycodin D & 1224 \\
8 & Unknown-2 & - \\
9 & Mixture (polygalacin D 2+3'-O-acetyl- & $1370+1266$ \\
& platycodin D) & \\
10 & Polygalacin D & 1208 \\
11 & 3'-O-Acetyl-polygalacin D & 1266 \\
12 & Unknown-3 & - \\
13 & 2'-O-Acetyl-platycodin D & 1266 \\
14 & Unknown-4 & - \\
\hline ge Putative compound. &
\end{tabular}




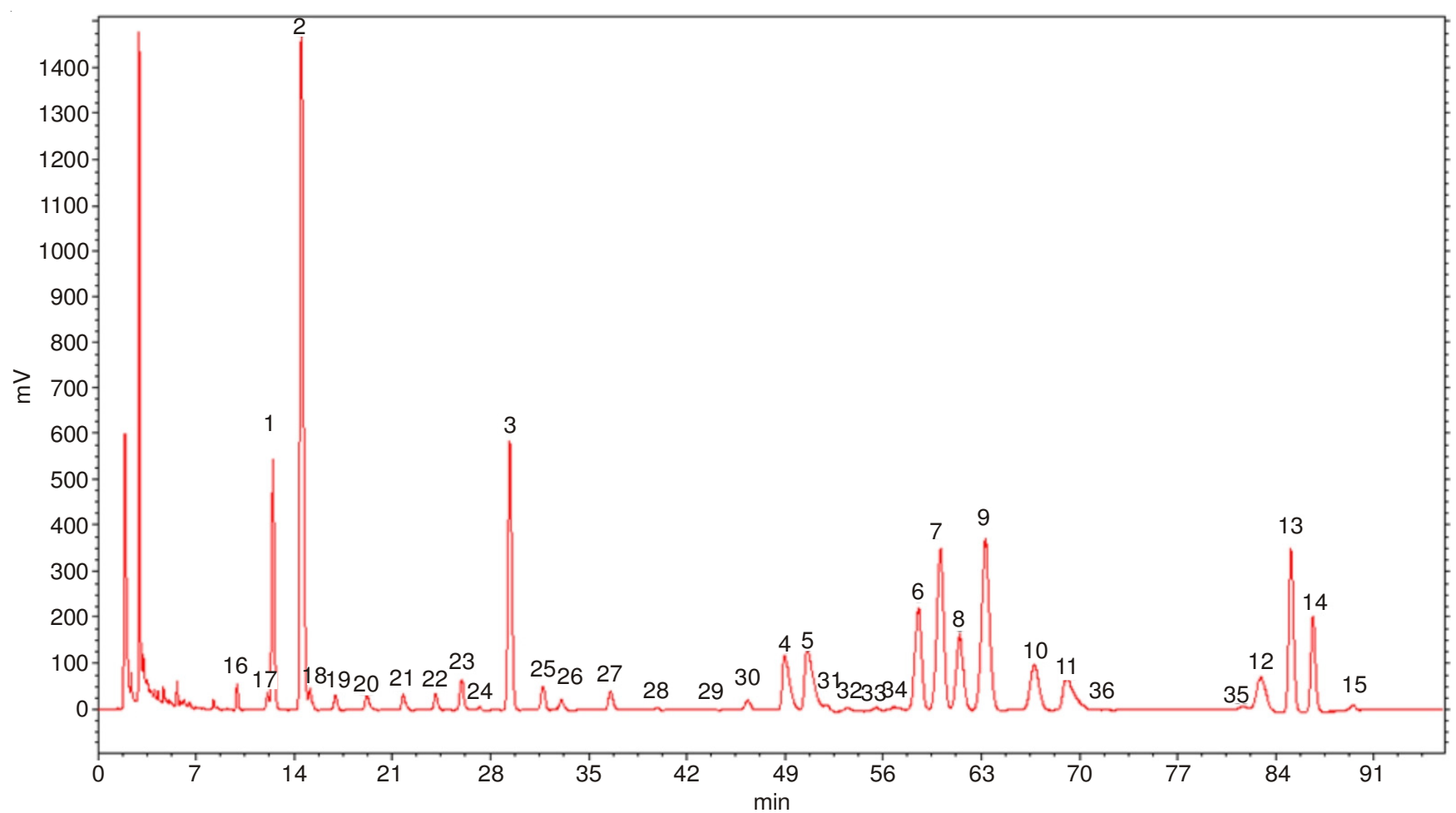

Fig. 1. HPLC profiles of saponins isolated from 2-year-old-root of Platycodi radix. 21. Peak numbers refer to the saponins listed in Table-1. Peak No. 1. Deapio-platycoside E; 2. Platycoside E; 3. Platycodin D3; 4. Platyconic acid A; 5. Unknown-1; 6. Platycodin D2; 7. Platycodin D; 8. Unknown-2; 9. Mixture (polygalacin D2+3'-O-acetyl-platycodin D); 10. Polygalacin D; 11. 3'-O-Acetyl-polygalacin D; 12. Unknown-3; 13. 2'-O-Acetyl-platycodin D; 14. Unknown-4

Variation of triterpenoidal saponin contents: Platycodi radix was collected from different regions of Korea, so it was expected that the platycoside contents in the samples would be varied with different cultivation areas. Samples collected from 19 different places were analyzed and the components were separated and identified. The triterpenoidal saponin contents ranged from 2,643 to $23,599 \mathrm{mg} / \mathrm{kg}$ dry weight (DW) in the 3-year-old roots and from 5,693 to $34,205 \mathrm{mg} / \mathrm{kg}$ DW in the 2-year-old roots, respectively (Tables 2 and 3). On the average, the content $(16,613)$ in the 2 year-old roots was higher platycodin D were notice in all the samples. Platycoside E and mixture of polygalacin D2 and 3'-O-acetyl-platycodin D found as the highest compounds in both 2- and 3-year-old roots. Platyconic acid A, platycodin D2 and platycodin D were only detected in 2-5 places and found less than $140 \mathrm{mg} / \mathrm{kg}$ DW. Platycodin D, a main compound of biological activity, was found very little amounts as 128 (1.17\% of the total) and $138(0.83 \%) \mathrm{mg} / \mathrm{kg}$ DW in 2- and 3-year-old roots, respectively and only detected limited collecting places. Moreover,

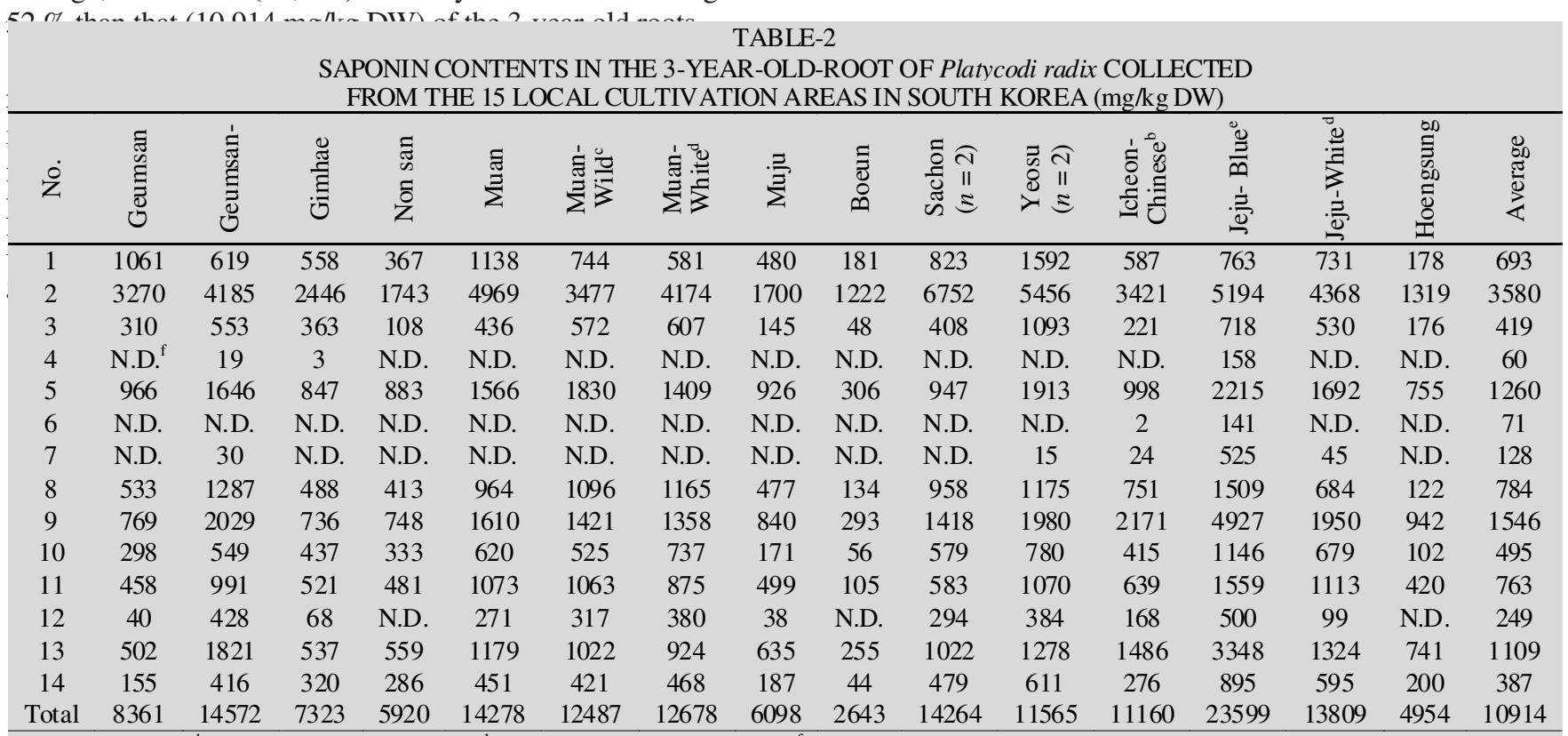

${ }^{\mathrm{a}}$ Retention time, ${ }_{\mathrm{b}}^{\mathrm{b}}$ Chinese seeds, ${ }^{\mathrm{c}}$ Wild type, ${ }^{\mathrm{d}}$ White flowers, ${ }^{\mathrm{e}}$ Blue flowers, ${ }^{\mathrm{f}}$ Not detected, ${ }^{\mathrm{g}}$ Putative compound. 
TABLE-3

SAPONIN CONTENTS IN THE 2-YEAR-OLD-ROOT OF Platycodi radix COLLECTED FROM THE 15 LOCAL CULTIVATION AREAS IN SOUTH KOREA (mg/kg DW)

\begin{tabular}{|c|c|c|c|c|c|c|c|c|c|c|c|c|c|c|c|c|}
\hline$\dot{0}$ & $\stackrel{\Xi}{\stackrel{\Xi}{\Sigma}}$ & 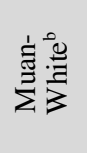 & 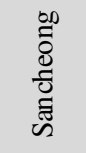 & 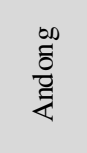 & $\begin{array}{l}\overrightarrow{0} \\
0 \\
0\end{array}$ & 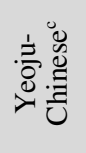 & 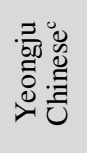 & 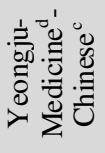 & 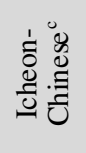 & 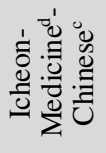 & $\begin{array}{l}\tilde{B} \\
\ddot{\theta}\end{array}$ & 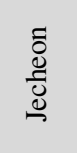 & $\underset{\Xi}{\Xi}$ & 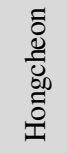 & 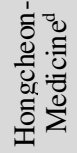 & 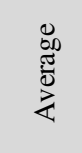 \\
\hline 1 & 1418 & 939 & 1494 & 1337 & 1024 & 921 & 825 & 425 & 443 & 205 & 639 & 587 & 1377 & 693 & 192 & 834 \\
\hline 2 & 5161 & 5648 & 5437 & 5018 & 8360 & 4492 & 6135 & 3167 & 3033 & 1821 & 4422 & 2770 & 6083 & 3093 & 1943 & 4439 \\
\hline 3 & 646 & 610 & 1184 & 341 & 2654 & 1753 & 1170 & 310 & 329 & 79 & 914 & 206 & 708 & 242 & 242 & 759 \\
\hline 5 & 2130 & 2187 & 2937 & 1148 & 4034 & 3436 & 3119 & 687 & 1500 & 683 & 1557 & 1121 & 1808 & 647 & 1219 & 1881 \\
\hline 6 & N.D. & N.D. & N.D. & N.D. & 113 & N.D. & 132 & N.D. & 17 & N.D. & N.D. & N.D. & N.D. & N.D. & N.D. & 87 \\
\hline 7 & N.D. & N.D. & N.D. & N.D. & 126 & 142 & 335 & 14 & 128 & N.D. & 14 & N.D. & 205 & N.D. & N.D. & 138 \\
\hline 8 & 1291 & 1769 & 1593 & 592 & 3715 & 2219 & 2854 & 747 & 1136 & 257 & 910 & 445 & 835 & 121 & 58 & 1236 \\
\hline 9 & 1819 & 2174 & 3223 & 1273 & 4318 & 4761 & 5714 & 1317 & 2779 & 719 & 1855 & 1134 & 4379 & 976 & 1521 & 2531 \\
\hline 10 & 992 & 1003 & 1441 & 364 & 1125 & 1165 & 1247 & 396 & 569 & 119 & 552 & 380 & 991 & 102 & 171 & 708 \\
\hline 11 & 1443 & 1398 & 2094 & 634 & 2627 & 2529 & 2102 & 732 & 981 & 359 & 926 & 688 & 1385 & 341 & 747 & 1266 \\
\hline 14 & 561 & 719 & 1062 & 289 & 965 & 968 & 877 & 403 & 521 & 701 & 491 & 401 & 498 & 232 & 235 & 595 \\
\hline Total & 17091 & 18758 & 23336 & 11840 & 34205 & 26982 & 29786 & 9234 & 13809 & 5693 & 13816 & 8501 & 21553 & 7112 & 7486 & 16613 \\
\hline
\end{tabular}

${ }^{\mathrm{a}}$ Retention time, ${ }^{\mathrm{b}}$ White flowers, ${ }^{\mathrm{c}}$ Chinese seeds, ${ }^{\mathrm{d}}$ Medicine type, ${ }^{\mathrm{e}}$ Medicine type, ${ }^{\mathrm{f}}$ Not detected, ${ }^{\mathrm{g}}$ Putative compound.

it was not found in the 1- and 4-year-old roots (data not shown).

Amongst the average platycoside values from the different cultivation areas platycoside E showed the highest content $(3,580 \mathrm{mg} / \mathrm{kg} \mathrm{DW})$, followed by mixture of polygalacin D2 and 3'-O-acetyl-platycodin D (1,546 mg/kg DW) and three unknown-1 compound (1,260 mg/kg DW) 3-year-old roots. Two-year-old roots obtained from Yeosu region showed the highest total saponin contents $(34,205 \mathrm{mg} / \mathrm{kg}$ DW). Deapioplatycoside $\mathrm{E}$ identified as the major saponin in both 2- and 3 -years-old roots contributed 16-47\% of total saponins even though in some region (Yeoju-Chinese seeds) exhibited lower content $(4,492 \mathrm{mg} / \mathrm{kg} \mathrm{DW})$. Han et al. ${ }^{11}$ reported that the mixture of crude saponins obtained from Platycodi radix significantly decrease body weight and growth of adipose tissues by inhibiting the activity of pancreatic lipase, thereby fat absorption in the small intestine has been limited. Kwon et al. ${ }^{12}$ claimed that the crude saponins decreased body weight and fat in mild type 2 diabetic rats. All the unknown compounds distributed comparatively similar in all region sample and shared average $24 \%$ in total saponins, whereas sample from Iksan region showed significant amount of unknown compound and contributed $35 \%$ of the total contents. It was suspected that this mixture of unknown compounds may have pharmacological effect since Han et al. ${ }^{11}$ reported that the mixture of crude saponins significantly decrease body weight and growth of adipose tissues by inhibiting the activity of pancreatic lipase, thereby fat absorption in the small intestine has been limited. Kwon et al..$^{12}$ claimed that the crude saponins decreased body weight and fat in mild type 2 diabetic rats.

The relative content of the individual platycosides between the cultivated areas was widely varied, thereby indicating that the assessment of saponins content of Platycodi radix would be effective. KFDA has not assigned any individual compounds for the quality control of balloon flowers or Platycodi radix ${ }^{4}$. Considerably, we would like to suggest using Platycodi radix from the region of Jinan since the samples contains moderate total saponins contents. In our study the amount of deapio- platycoside E, platycosides E, mixture of polygalacin D2 and 3'-O-acetyl-platycodin D and polygalacin D2 were dominant in all the geographical places. The results showed that if one compound was high in content, the other compounds in same region exhibited very low in amounts, so that the sum of the four metabolites remained approximately constant. The average of deapio-platycoside E, platycosides E, mixture of polygalacin D2 and 3'-O-acetyl-platycodin D and polygalacin D2 for the fifteen cultivated regions were 693, 3,580, 1,546 and $763 \mathrm{mg} /$ $\mathrm{kg}$ DW respectively in 3-year-old roots, whereas in two years root the average content were 883, 4,439, 2,531 and 1,266 $\mathrm{mg} / \mathrm{kg}$ DW.

\section{Conclusion}

HPLC and ESI-MS analysis guided identification and quantification of 10 known and 4 unknown saponins from the roots of Platycodi radix collected from different cultivated in different the Korean peninsula. Known compounds such as deapio-platycoside E, platycoside E, platycodin D3, platyconic acid $\mathrm{A}$, platycodin $\mathrm{D} 2$, platycodin $\mathrm{D}$, mixture of polygalacin D2 and 3'-O-acetyl-platycodin D, polygalacin D, 3'-O-acetylpolygalacin D and 2'-O-acetyl-platycodin D were observed in majority of the Platycodi radix roots. The triterpenoidal saponin contents ranged from 2,643 to $23,599 \mathrm{mg} / \mathrm{kg}$ DW in the 3 -year-old roots and from 5,693 to $34,205 \mathrm{mg} / \mathrm{kg} \mathrm{DW}$ in the 2 -year-old roots, respectively. Platycoside $\mathrm{E}$ and the mixture of polygalacin D2 and 3'-O-acetyl-platycodin D were identified as the highest compounds in the 2 and 3 -year-old roots. Individual platycosides between the cultivated areas were widely distinguished. However, Yeosu region exhibited high total saponins.

\section{ACKNOWLEDGEMENTS}

This work was carried out with the support of Cooperative Research Program for Agriculture Science \& Technology Development (PJ006458) Rural Development Administration, Republic of Korea. The authors also thanks Addiriyah Chair for 
Environmental Studies, Department of Botany and Microbiology, College of Science, King Saud University, Saudi Arabia for partial finance assistance.

\section{REFERENCES}

1. Y.P. Kim, E.B. Lee, S.Y. Kim, D. Li, H.S. Ban, S.S. Lim, K.H. Shin and K. Ohuchi, Planta Med., 67, 362 (2001).

2. B.J. Xu, Y.N. Zheng and C.K. Sung, Nat. Prod. Sci., 10, 141 (2004)

3. W.W. Fu, D.Q. Dou, N. Shimizu, T. Takeda, Y.H. Pei and Y.J. Chen, J. Nat. Med., 60, 68 (2008)

4. Y.K. Dae, S.K. Young, Y.R. Shi, H.C. Yeon, C. Mi-Ran, J.Y. Hye and P. Sunmin, Eur. J. Nutr., 51, 529 (2012).

5. H.I. Son, Y.H. Park, S.I. Lee, H.D. Yang and H.I. Moon, Molecules, 12 , 1147 (2007).
6. J.Y. Kim, Y.P. Hwang, D.H. Kim, E. Han, Y.C. Chung and S.H. Roh, Biosci. Biotechnol. Biochem., 70, 858 (2006).

7. Y. Xie, H.X. Sun and D. Li, Vaccine, 27, 757 (2009).

8. G.S. Kim, H.T. Kim, J.D. Seong, H.S. Park and S.D. Kim, Korean J. Med. Crop. Sci., 10, 200 (2002)

9. Y.C. Na, Y.W. Ha, Y.S. Kim and K.J. Kim, J. Chromatogr. A, 1189, 467 (2008).

10. L.R. Snyder, J.J. Kirkl and J.L. Glajch, Practical HPLC Method Development, Wiley, New York (1997).

11. L.K. Han, Y.N. Zheng, B.J. Xu, H. Okuda and Y. Kimura, J. Nutr., 132, 2241 (2002).

12. D.Y. Kwon, Y.S. Kim, S.M. Hong and S. Park, Br. J. Nutr., 101, 358 (2009). 